\title{
Ouro Preto, Água Limpa: O Abastecimento Doméstico de Água no Epicentro do Ciclo do Ouro
}

\author{
Alberto de Freitas Castro Fonseca \\ Faculty of Environmental Studies, University of Waterloo - ON, Canada \\ adfonsec@fes.uwaterloo.ca \\ José Francisco do Prado Filho \\ Programa de Pós-graduação em Engenharia Ambiental - PROÁGUA -UFOP - MG \\ jfprado@depro.em.ufop.br
}

Recebido: 26/05/08 - revisado: 18/07/08 - aceito: 05/09/08

\begin{abstract}
RESUMO
Este artigo aborda o abastecimento doméstico de água em Ouro Preto, MG, durante o ciclo do ouro. Nesta época, ocorreu um dos mais relevantes episódios do gerenciamento dos recursos hídricos brasileiros no periodo colonial, no qual foi instaurado um primitivo sistema de licença de uso de águas, bem como uma legislação determinando a mineração como o uso prioritário. Neste contexto, procurou-se entender quais eram os problemas relacionados ao abastecimento de água na Vila e como o poder público local procurou solucioná-los. Os métodos utilizados na pesquisa contemplaram revisões bibliográficas, entrevistas, inspeções de campo e uma extensa consulta documental em arquivos públicos. As pesquisas comprovaram que a demanda por água durante o ciclo do ouro foi intensa não apenas nos serviços de mineração, mas também nos novos centros urbanos. No caso de Vila Rica, como era conhecida Ouro Preto na época, esta demanda se traduziu na construção de chafarizes públicos e particulares, na cobrança de taxas pela posse de água pública e na instauração de posturas urbanas coibindo irregularidades no uso da água. Alguns documentos pesquisados comprovam que ocorreram prisões e aplicações de multas devido ao descumprimento destas medidas. Foram identificados aspectos técnicos e culturais no sistema de abastecimento que se diferenciam dos observados nas cidades litorâneas da época. Passados quase três séculos, o sistema de abastecimento de águas de Ouro Preto ainda guarda muito das suas antigas características, tais como dezenas de pontos captação, falta de medição de consumo e problemas relacionados à quantidade e qualidade da água fornecida à população. Espera-se que as informações aqui geradas possam auxiliar o recém criado Serviço Municipal de Água e Esgotos de Ouro Preto e demais serviços gestores de saneamento a tomarem decisões mais conscientes das variáveis históricas e culturais relacionadas ao controle e uso da água. No caso de Ouro Preto, uma cidade considerada Patrimônio Cultural da Humanidade, tais variáveis são essenciais.
\end{abstract}

Palavras-chave: História da Água; Abastecimento de Água; Saneamento; Ouro Preto (MG).

\section{INTRODUÇÃO}

Um dos mais importantes relatórios internacionais sobre o estado do meio ambiente concluiu em 2007 que o bem-estar humano e diversos ecossistemas mundiais estão sendo seriamente afetados por mudanças no ciclo hidrológico causadas por pressões humanas. Se mantidas as atuais tendências de crescimento populacional, urbanização e consumo de recursos naturais, quase dois bilhões de pessoas morarão em países ou regiões de absoluta escassez de água até 2025 (UNEP, 2007, p. 116). Um relatório nacional sobre o estado dos recursos hídricos concluiu em 2006 que ainda persistem diversos pro- blemas de esgotamento sanitário, racionamento de água e conflitos entre usuários no Brasil (MMA/SRH, 2006). Tais diagnósticos são importantes, pois confirmam que, apesar dos avanços positivos ocorridos na última década, resta desafiadora a "crise da água".

Para lidar com este desafio, profissionais, acadêmicos, políticos, ativistas vêm se ocupando de diversas ações, tais como: estímulo ao uso múltiplo e integrado, melhoria dos sistemas de informações hidrológicas, aprimoramentos institucionais, capacitação de pessoal, desenvolvimento tecnológico e construção de infra-estruturas. Todas essas ações, porém, dependem de um melhor entendimento da relação da humanidade com a água, o qual, por sua 
vez, depende da história. Em 1998, Jerome Pricoli, editor chefe do periódico Water Policy, escreveu um artigo enfatizando a importância da história para embasar políticas de água e construir um novo realismo ecológico. "A reflexão histórica pode nos prover um senso de otimismo, de fé na criatividade humana e na resiliência da natureza para balancear nosso pessimismo" (Priscoli, 1998, p. 624).

Corroborando a percepção deste autor, diversas instituições vêm promovendo este conhecimento na última década. Dentre as mais relevantes, destaca-se a Associação Internacional de História da Água, que realiza conferências internacionais sobre o tema desde 1999. No Brasil, a Agência Nacional de Águas (ANA), em parceria com a United Nations Educational, Scientific and Cultural Organization (UNESCO), anunciou recentemente a produção de um robusto livro sobre a história do uso da água no Brasil $^{1}$, o qual deverá ser publicado em 2009. Há hoje uma vasta literatura focando a história da relação da humanidade com a água sob prismas panorâmicos, técnicos, culturais, religiosos e administrativos. Mas, no Brasil, esta história ainda não foi muito abordada.

Este artigo objetiva contribuir para esta área de conhecimento, ao pesquisar o abastecimento de água doméstico na cidade de Ouro Preto, Minas Gerais, durante o período colonial. Vila Rica, como era então conhecida Ouro Preto, foi o epicentro não apenas do ciclo do ouro, mas também de um dos mais relevantes episódios do gerenciamento de recursos hídricos na América Portuguesa (Fonseca e Prado Filho, 2006). Em seus solos, ocorreram diversos conflitos por posse de água e foi instaurado, em 1720, um primitivo sistema de permissão de uso (algo semelhante às atuais outorgas de recursos hídricos), bem como uma legislação conferindo à mineração o uso prioritário. Afinal de contas, dizia um adágio da época: "sem água, de nada vale uma serra de ouro" (Ferrand, 1998).

O presente trabalho avança o artigo de Fonseca e Prado Filho e procura entender as implicações que a valorização dos recursos hídricos e os respectivos conflitos e mecanismos gerenciais tiveram para o abastecimento de água no contexto urbano. Como se deu o uso da água nas residências e em logradouros públicos? Quais foram os principais problemas relacionados à água na Vila? Como o poder público local procurou solucioná-los?

Espera-se que as respostas para tais perguntas, apresentadas a seguir, auxiliem os atuais gesto-

\footnotetext{
${ }^{1}$ Para mais informações: http:/ / historiada agua.ana.gov.br/ (Acesso em 13 de abril de 2008).
}

res de serviços de saneamento a tomarem decisões mais conscientes das variáveis históricas e culturais relacionadas ao controle e uso da água.

\section{ASPECTOS METODOLÓGICOS}

Diante da escassez de publicações sobre o tema, as pesquisas contemplaram, além de revisões bibliográficas, uma extensa consulta documental referente ao período 1720-1820 nos arquivos públicos de Minas Gerais, de Ouro Preto e do Museu da Inconfidência. Também foram realizadas consultas às obras raras da Biblioteca Nacional e no Museu do Paço Imperial, bem como entrevistas com moradores e funcionários públicos de Ouro Preto. A fim de facilitar a leitura, a transcrição dos manuscritos setecentistas aqui citados foi adaptada à atual ortografia da língua Portuguesa.

\section{O USO DA ÁGUA}

O surgimento de Vila Rica, embora difícil de precisar, ocorreu em fins da década de 1690 e é usualmente atribuído ao episódio narrado por Antonil em sua famosa obra de 1711, Cultura e Opulência do Brasil. De acordo com Antonil (1982), um mulato indo ao sertão com uns paulistas a buscar índios,

(...) chegando ao cerro Tripuí desceu abaixo com uma gamela para tirar água do ribeiro que hoje chamam do Ouro Preto, e, metendo a gamela na ribanceira para tomar água, e roçando-a pela margem do rio, viu depois que nela havia granitos da cor do aço, sem saber o que eram, nem os companheiros, aos quais mostrou os ditos granitos, não souberam conhecer e estimar o que se tinha achado tão facilmente, e só cuidaram que ai haveria algum metal não bem formado, e por isso não conhecido. Chegando, porém, a Taubaté, não deixaram de perguntar que casta de metal seria aquele. E, sem mais exame, venderam a Miguel de Souza alguns destes granitos, por meia pataca de oitava, sem saberem eles o que vendiam, nem o comprador que cousa comprava, até que se resolveram a mandar alguns dos granitos ao governador do Rio de Janeiro, Artur de Sá; e, fazendo-se exame deles, se achou que era ouro finissimo. (p. 164)

Esta narrativa, lendária ou não, é bastante curiosa, pois atribui o descobrimento do ouro ao fortuito abastecimento de água do mulato, e, nesse 
sentido, simboliza a importância que a água terá na história de cidade. Divulgada a notícia do ouro, milhares de pessoas - quem, diga-se de passagem, se encaixavam no tipo que Holanda (2002, p. 44) chamou de aventureira, cujo ideal será colher o fruto sem plantar a árvore - rumaram para a região, depois batizada de Vila Rica, na esperança de se enriquecerem. Organizaram, então, povoados em volta de capelas provisórias, cujos adros tornam-se os primeiros logradouros públicos.

Nessa época, as ações voltadas ao abastecimento de água foram eminentemente individuais, isto é, sem a interferência do poder público. Para seus misteres, os primeiros mineiros improvisaram diversos tanques ou bicas (Vasconcelos, 1977). A região dispunha de copiosos mananciais de água e, nesse sentido, é muito provável que, nos primeiros anos, não tenha havido o problema da falta de água, sendo a disponível mais do que suficiente para matar a sede dos mineradores e animais, para a higiene e para os serviços de mineração. Mas o fortíssimo crescimento populacional da Vila logo trouxe o problema da fome (Sales, 1965, p. 24-26). Nesse cenário, é de se supor que tenha havido diversos conflitos em torno da posse da água. O que, infelizmente, não se pode atestar em função da falta de documentos referentes a esse período. Somente depois de consolidada a Vila, isto é, por volta de 1720, quando foi montado um aparato burocrático para a administração urbana, é que ficaram registrados maiores detalhes do abastecimento de água.

\section{A água nas residências}

Comparada às cidades litorâneas da colônia, Vila Rica foi bastante privilegiada no que se refere às condições para saneamento básico. Em função da sua topografia e dos seus numerosos mananciais de água, não eram necessárias grandes obras de captação e condução das águas, e tampouco grandes esforços para se realizar o esgotamento sanitário.

No Rio de Janeiro, até meados do século XIX (Silva, 1975), os despejos sanitários - águas servidas, conteúdo de urinóis e retretes - eram guardados em tinas "num canto do jardim ou de pequeno pátio contíguo à casa, colocado atrás de uma cerca de trepadeiras, ou simplesmente escondido por duas ou três tábuas apoiadas ao muro" (Debret, 1972, p. 133). Ao anoitecer, os escravos, conhecidos como tigres, iam despejá-las nas praias, rios e terrenos baldios. Em muitas casas, porém, como afirma Castro (2003, p. 32), os despejos eram feitos nas próprias ruas, trazendo grandes inconvenientes à população.
Em Vila Rica, entretanto, parece que não existiram esses tigres, ${ }^{2}$ porque as águas servidas podiam escoar facilmente, através de valos (Representação... 1746a), para os córregos que passavam nos fundos dos quintais ou para as sarjetas das ruas ${ }^{3}$. Além disso, completa Castro (2003, p. 33), no interior do país, o sistema de estocagem de detritos era pouco utilizado, uma vez que, no grosso dos casos, a profundidade do lençol freático permitia a construção de sumidouros e fossas.

É interessante notar que, até o final do século XIX e começo do século XX, era rara a existência de cômodos nas residências reservados às atividades higiênicas, o que significa que a água podia ser utilizada em todos os aposentos. Exemplo precoce de um espaço especializado para as atividades higiênicas pode, ainda hoje, ser observado na Casa dos Contos em Ouro Preto (FIG. 1). Quanto aos objetos domésticos relacionados ao uso da água nas residências, constam, na bibliografia e nos documentos pesquisados, vasos, tonéis, barris, gamelas, pias, tanques, urinóis, bacias e jarros.

Observa-se também que algumas residências coloniais possuíam seus próprios chafarizes. Isso se deu, no caso de Vila Rica, quando os proprietários possuíam nascentes d'água nos próprios terrenos porque, neste caso, as águas eram, juridicamente, consideradas de direito do dono do terreno - ou quando os particulares solicitavam licença do Senado da Câmara ${ }^{4}$ para "tirar" água do encanamento público, a exemplo do que fez um capitão em 1782. Disse o capitão ao Senado da Câmara que

(...) para melhor cômodo de suas casas que tem no Ouro Preto ${ }^{5}$, carece que vosmecê lhe concedam um anel de água, tirada do encanamento público, que passa na rua Nova do Sacramento, em pia assentada onde mais conveniente(...), [pagando para isso] (...) trinta e duas oitavas de ouro, com a obrigação de que no caso que falte algum dia a dita água ao público não duvidará o suplicante largar mão dela. (Requerimento... 1782)

\footnotetext{
${ }^{2}$ Nas pesquisas realizadas nos fundos dos arquivos públicos, não se observou referência sobre esses escravos.

${ }^{3}$ A vila foi crescendo de maneira que as residências dessem os fundos para os córregos, fazendo-os de "vergonhosos" canais de escoamento das águas servidas.

4 Os Senados da Câmara eram análogos às atuais prefeituras municipais. No Rio de Janeiro a concessão do direito de canalizar as águas dos aquedutos públicos para as casas de particulares só se deu em 1840 (Oliveira, 1991, p. 45 apud Castro, 2003, p. 35) ${ }^{5}$ Antigo bairro de Vila Rica.
} 
Segundo Oliveira, no Rio de Janeiro, a concessão do direito de canalizar as águas dos aquedutos públicos para as casas de particulares só se deu em 1840 (Oliveira, 1991, p. 45 apud Castro, 2003, p. 35). Nos documentos pesquisados, porém, foram identificados requerimentos particulares de água pública em Vila Rica já na década de 1780.

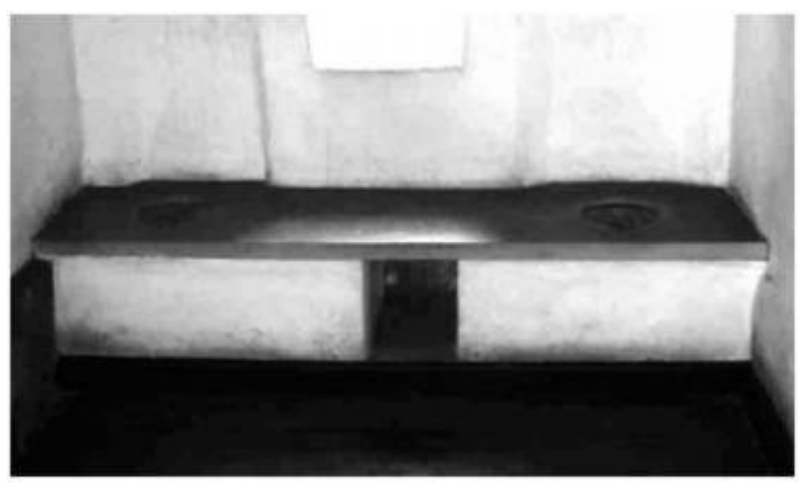

Figura 1 - Cômodo higiênico, evidenciando dois assentos sanitários em madeira (Casa dos Contos, Ouro Preto, MG). Fotografia de Alberto Fonseca (Fev/2004).

Ao contrário dos chafarizes públicos, os chafarizes particulares foram muito pouco estudados, de maneira que não se sabe ao certo se eles eram freqüentes nas residências. É provável que eles tenham se multiplicado à medida que a mineração entrou em decadência, isto é, à medida que a população decaiu e aumentou a disponibilidade de água na sede urbana. Ainda hoje, observam-se, em diversas casas de Ouro Preto, esses chafarizes privados, ou, pelo menos, resquícios deles. Aqueles poucos que ainda conservam suas datas referemse a períodos posteriores ao apogeu da produção aurífera.

\section{Fontes e Chafarizes Públicos}

Os chafarizes ${ }^{6}$ públicos coloniais de Ouro Preto, em sua maioria construída durante o governo de Gomes Freire de Andrade (1735-1763), são, como diz Mello (1985, p. 217), "do tipo parietal, à feição de frontispício de capela”. Dois ou mais motivos concorriam na época para que se aplicassem aos

\footnotetext{
${ }^{6}$ Fonte e Chafariz - pode-se inferir a partir do dicionário do Bluteau (1712) - eram, na época, sinônimos com etimologias distintas.
}

chafarizes o "partido" frontal, à moda das fontes rústicas italianas.

\begin{abstract}
O primeiro motivo era de caráter exclusivamente econômico. Os chafarizes desenvolvidos em espaldar, à moda italiana, eram menos dispendiosos, do que àqueles [sic] que se construíam no centro das praças. $O$ segundo motivo era de ordem apenas urbanística. Sendo raras as praças - os "rocios" como as nomeia o grave Monsenhor José Pizarro - nem sempre elas podiam vir a ser aproveitadas para os chafarizes públicos. Aliás, outra razão de não pequena importância, poderia ainda ser lembrada: a conveniência de servirem, certos chafarizes, ou quase todos, de bebedouro às alimárias. (Mariano Filho, 1943, p. 10)
\end{abstract}

No caso de Vila Rica, a falta de praças não se constituía um motivo relevante, tendo em vista a relativa abundância destas observada nos primeiros mapas urbanos (Mappa... 1785-1800). O verdadeiro motivo era mesmo de caráter econômico. Numa região onde água significava ouro, não cabia desperdício com fontes suntuosas, nas quais o caráter artístico superasse o caráter utilitário. Isto explica, ademais, a simplicidade e a falta de originalidade dos riscos. Em sua maioria coroados com cruzes, escudos, volutas e pinhas (Mello, 1985, p. 216), e adornados com carrancas, figuras mitológicas e elementos aquáticos, os chafarizes não apresentam nada que rompa com os moldes em uso na época, nos quais o profano se conforma com o sagrado. Nem mesmo o chafariz do Alto da Cruz, cujo busto à mostra ganhou fama depois de ter sido atribuído a Aleijadinho por Lúcio Costa e ser tão valorizado por Sylvio de Vasconcelos (1979). Ainda assim, no modesto panorama das fontes coloniais, Ouro Preto se destaca pela quantidade (durante a pesquisa e inspeções de campos, foram identificados e registrados 32 chafarizes, número bem superior ao já relatado nas publicações que trataram do tema). Quanto à qualidade, só perde para o Rio de Janeiro e os vetustos chafarizes do Mestre Valentim.

O morador ou turista hoje, ao se deparar com os chafarizes coloniais sobejantes de Ouro Preto, poderá supor que eles ainda conservam suas formas, detalhes e local originais. A verdade, isto é, as fontes documentais, porém, mostram que parte deles teve seus tanques e carrancas ou trocados ou suprimidos. Mostram também que, em função das vicissitudes urbanas, muitos tiveram que mudar de lugar. Como no caso de um antigo chafariz da Ponte 
do Ouro Preto que, em 1846, foi mandado para a Praça Tiradentes, junto à Câmara e Cadeia, ficando em seu lugar um outro que restava enterrado no bairro Padre Faria. Nesta mesma praça, aliás, já existiu um outro chafariz, em frente de onde hoje se situa uma sede regional do Instituto do Patrimônio Histórico e Artístico Nacional (IPHAN). Também tiveram seus lugares alterados os chafarizes Dos Contos, Do Rosário, Do Quartel, Do Alto das Cabeças, dentre outros. Um mapa de Vila Rica do final do século XVIII (Mappa... 1785-1800) mostra a localização original de grande parte deles, e evidencia também que alguns, como o da rua dos Paulistas e o do Passa-Dez, não existem mais.

Dos autos de arrematação desses chafarizes - grande parte transcrita por Feu de Carvalho (1936) -, depreende-se seus aspectos técnicoconstrutivos. A água era captada em minas de propriedade do Senado, tendo-se o cuidado de protegêlas com "porta de canela preta" e fechadura "forte e grossa”. O arrematante devia seguir o risco a ele repassado pelo Senado da Câmara e terminar o serviço num tempo que, a depender da complexidade da obra, variava de três a nove meses. Caso não cumprisse o prazo, teria o pagamento descontado. O material preferencialmente empregado nos tanques, ornatos e muro era a pedra do Itacolomy (da mais branca) ou a de Tapanhoacanga. Os encanamentos, por sua vez, eram feitos de telha bem grossa, alcatruzes de barro vidrado ou de pedra betumados com azeite do reino. As carrancas, quando determinadas, seriam tantas quantas fossem as bicas, feitas de bronze ou de pedra. O pagamento era feito em duas (início e fim da obra) ou três parcelas (início, meio e fim da obra).

Com o tempo, esses chafarizes sofriam estragos - "devido aos barris que neles se colocavam para colher a água” (Carvalho, 1936, p.120), às vicissitudes urbanas ou às intempéries. $O$ conserto ficava a cargo do arrematante do serviço de conservação de fontes, pontes e calçadas da vila:

(...) será obrigado o dito arrematante a conservar, reparar e reedificar todas as fontes que pertencem ao senado em tudo o que for necessário em seus encanamentos, fazendo socalcos aonde forem necessários, e tudo o mais que necessário for que corram as águas desembaraçadas para as fontes deste Senado, visitando os registros e alimpando os tanques e concertá-los aonde for necessário e desembaraçando tudo em modo que não haja faltas de água nas ditas fontes nem disso sequer nem os povos e aonde houver bicas as cobrira com tábuas de canelas pretas.(Termo... 1750)
Um aspecto interessante dos chafarizes são as carrancas ou gárgulas. Embora estas, originalmente, significassem a "representação de uma cara ridícula e deforme que se põe nos tanques e bota água“ (Bluteau, 1712), eram empregadas para designar qualquer ornato que se colocasse na bica, fosse "cara ridícula", detalhe geométrico, ser fantástico, animal, isto é, eram empregadas confusamente no sentido de gárgula: termo da arquitetura que primitivamente designava a abertura ou o orifício por onde se escoava a água (principalmente do telhado), e que, com o tempo, passou a significar também os ornatos utilizados nessas aberturas.

Se se toma as carrancas no sentido de gárgula, como o fez Laterza (1983) no seu ensaio sobre a gárgula barroca mineira, torna-se mais fácil "vasculhar" o uso desse elemento na história da arquitetura e da arte, e, com isso, apreender seu significado. As gárgulas aparecem em toda a história da arquitetura, a começar pelos antigos gregos e egípcios, sendo objeto de destaque, sobretudo, na arte românica e gótica. Entre suas funções não arquitetônicas, isto é, de proteger os edifícios da erosão da água, estão: educação religiosa da população iletrada, afastar os espíritos e proteger o edifício (tradição grega), representar os medos humanos, etc. Os motivos escolhidos para se construir as gárgulas eram muito variados e de diferentes origens. Encontramse temas bíblicos (como o utilizado no lavatório da sacristia da igreja São Francisco de Assis de Ouro Preto), pagãos, gregos, egípcios e da mitologia oriental. Entre esses, destacam-se: bestas, cães, leões, seres marinhos, humanos bizarros e quimeras.

No caso de Ouro Preto, predominou o uso de faces carrancudas, como as que se vê nos chafarizes do Passo, do Bonfim, do Vira-Saia (FIG. 2a) e de Marília de Dirceu. Mas também havia animais (FIG. 2b), seres fantásticos (FIG. 2c) e figuras mitológicas.

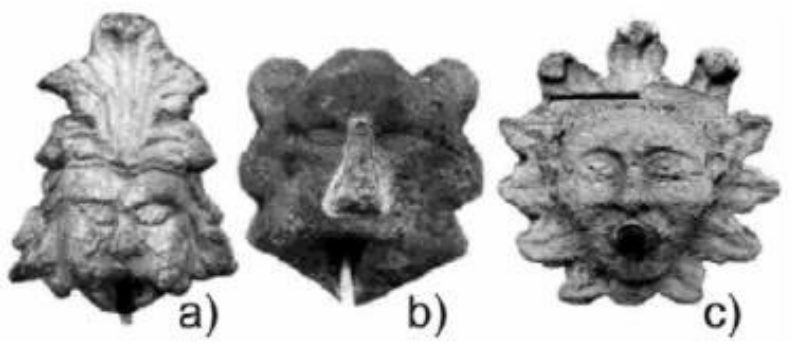

Figura 2 - Carrancas ouro-pretanas. a) Chafariz do ViraSaia; b) Chafariz do Quartel; c) Chafariz da escadaria do Museu da Inconfidência.

Fotografia de Alberto Fonseca (Dez/2003). 
Maltieria (1971, p. 108), ao descrever os chafarizes ouro-pretanos, confiou nas palavras de Alberto Pimentel (um arqueólogo português), segundo as quais, a água esguichada pelas bochechas das carrancas relembra o rito pagão de Céres, no qual os sacerdotes benziam as terras, borrifando-as, para se obter uma boa colheita. Interpretar, porém, o real significado ou até mesmo a real forma das carrancas ouro-pretanas não é tarefa fácil, uma vez que os riscos ou projetos dessas se perderam e não há, até o momento, fontes documentais que explicitem seu real significado. Tome, por exemplo, a carranca do chafariz dos Contos (FIG. 3) a qual não se sabe nem mesmo se se trata de um pelicano, de uma águia ou outro animal.

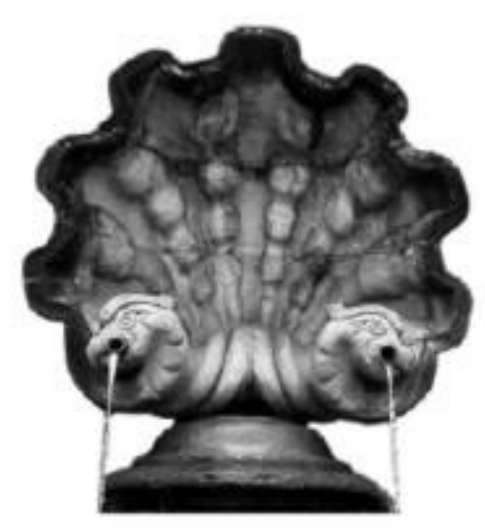

Figura 3 - Carranca do chafariz dos Contos. Fotografia de Alberto Fonseca (Dez/2003).

Nesse sentido, compete evitar interpretações unívocas e manter uma postura interrogativa diante dessas ornamentações. O mais provável é que o uso de gárgulas ou carrancas deu-se em Ouro Preto, assim como em outras cidades mineiras, mais por necessidade de ornamentar do que de se expressar simbolicamente. E, com efeito, não caberia atribuir aos moradores de Vila Rica uma consciência mítica diante da água, pelo simples fato de terem construído essas carrancas.

"Os chafarizes de Ouro Preto acompanharam o esvaziamento do lugar. (...) Sofreram concorrência direta dos encanamentos que irromperam pelo casario adentro" (Fontes... 1991, p. 93), sobretudo, a partir de 1890, quando foi inaugurado o novo sistema de água e esgotos da cidade. Hoje, a maioria deles não derrama água nos seus tanques. Perderam em funcionalidade, mas ganharam em monumentalidade. E ganhariam muito mais, se ainda vertessem o precioso líquido, pois como diz Symmens (1998, p. 21): Without the enlivening movement of water, fountains become inert and lose their sense of magic.

\section{PROBLEMAS E SOLUÇÕES NO ABASTECIMENTO DE ÁGUA}

Como observaram Fonseca e Prado Filho (2006, p. 10), o regime jurídico da água não estava bem definido nas Ordenações Filipinas ou em outros dispositivos jurídicos da época. De acordo com um antigo autor português (Moreira, 1920, p. 32), era reduzidíssimo o número das disposições legislativas sobre esta matéria, de modo que os praxistas se viam obrigados a aplicar os princípios do direito romano. Embora dissessem as Ordenações Filipinas em seu livro 2o, título 20o, §8o, que estavam incluídos nos direitos reais "os rios navegáveis, e os de que se fazem os navegáveis, se não caudais, que corram em todo tempo" e que, “(...) o uso das estradas e ruas públicas e os rios seja igualmente comum a toda a gente" (Almeida, 1870, p. 441), ou seja, embora as Ordenações dessem a entender que a água era um bem de domínio público, o que se observava na prática era que, em certos casos (rios intermitentes, nascentes em terrenos particulares), a água era considerada um bem particular, conforme os princípios do direito romano (Moreira, 1920). Nos casos de contendas pela posse de regos d'água ou nascentes utilizadas no abastecimento de água doméstico, competia ao Senado da Câmara da Vila interceder. Quando essas águas, porém, eram empregadas na mineração o julgamento ficava sob a competência dos guardas-mores (Fonseca e Prado Filho, 2006).

Na Vila Rica colonial, não ocorreu "planejamento", como hoje se entende, para o abastecimento de água, isto é, não se fez previsão do crescimento populacional, cálculo da taxa de consumo, etc. O sistema de abastecimento de água reagiu à demanda. Quando o povo reclamava, o Senado da Câmara procurava atendê-lo.

No Arquivo Público Mineiro foram identificados diversas reclamações de moradores referentes a problemas no abastecimento de água urbano. Dentre os mais significativos exemplos, estão:

- A da falta de fontes, como a que se lê na representação dos moradores do bairro Rosário: 
Dizem os Moradores do bairro do Rosário desta Vila abaixo assinados, que eles suplicantes padecem grave detrimento na falta de água para suas casas por lhes ser preciso conduzi-la de longe, e desejando remediar tão urgente necessidade determinam fazer uma fonte à sua custa, detrás do quintal da Igreja do Rosário, por ser parte cômodas [sic] para toda a vizinhança sem prejuizo de algum nem deste senado; e para isso carecem que o mesmo Senado lhes conceda uma suficiente porção de água, da que vem pela mesma parte para os moradores do Ouro Preto; como também se permita aos suplicantes mudarem para a mesma parte o tanque da fonte velha do Caquende; por estar ali inútil e não haver esperanças de que possa servir, por entulhado; e porque os suplicantes se querem empregar nesta obra tão útil ao bem comum, sem despesa deste Senado; só imploram a concessão da dita água por não fazer falta à que vem para o ouro preto como a vosmecês é notório nestes termos. (Representação... 1745a)

A da falta de água nos chafarizes públicos, como a que se lê na representação dos moradores das regiões do Piçarrão e Alto da Cruz:

Dizem os moradores do Piçarrão e Alto da Cruzes do Padre Faria que eles, suplicantes, experimentam muita falta de água para o seu ministério [sic], por causa desta faltar a um chafariz que se acha na dita paragem feito por este Senado, em cujos termos lhe é preciso aos ditos moradores recorrerem a vosmecê para que se dignem de lhe mandar meter água (...) (Representação... $1745 \mathrm{~b})$

A do estado de conservação das fontes, como a que se lê na representação dos moradores da freguesia de Antônio Dias:

Dizem os moradores de Antônio Dias desta Vila, que havendo na rua Direita um chafariz posto pelo Senado da Câmara e uma fonte firmada sobre uma bica de madeira no fundo dos quintais, que serve a sua água para o uso de se beber, muito úteis e necessárias ambas as aguada [sic] para o mister dos povos daquela freguesia, sucede que ambas elas, por se acharem arruinados os encanamentos e podre a dita bica de pau e entulhadas as minas onde tem o seu nascimento corre muita pouca ou nenhuma água daquela que lhe foi concedia pelo mesmo Senado. E por este tão justo mo- tivo, recorrem a vossa excelência para que se digne ordenar ao Procurador deste Senado da Câmara faça alimpar as ditas minas e seus encanamentos, e reformar a nova bica que se acha banida, para melhor expedição das ditas águas, visto que os mesmos moradores pagão foros das suas propriedades ao nobre Senado(...). (Representação... 1804)

- A do extravio de águas públicas para particulares, como a que se lê nesta representação dos moradores do morro do Pau Doce:

Dizem os moradores do Morro do Pau Doce desta vila que eles [ilegível] desta parte se acham na pacifica posse da quarta parte da água que sai da mina do mesmo morro para seus usos, além da extração do ouro, seguindo as mais partes para os moradores da rua das Cabeças até os da ponte do Rosário; e porque desta mesma se tem extraviado grande parte para casas particulares, necessariamente se há de experimentar falta no publico (...) e porque não é da intenção deste Senado lesar a uns para utilizar a outros; e como é constantemente sabido terem os suplicantes aquela porção de água; a vosmecê pertence a conservação dela. (Representação... 1806)

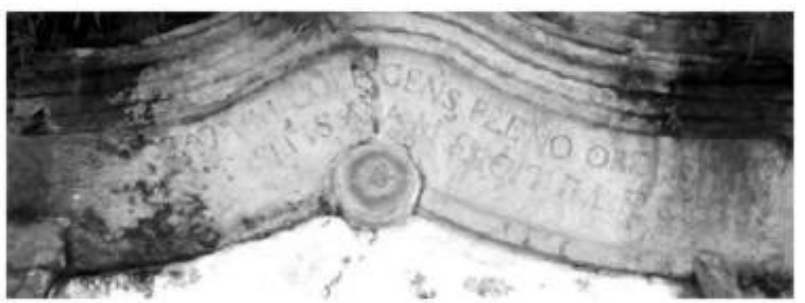

Figura 4 - Resquícios da inscrição latina do Chafariz dos Contos. Fotografia de Alberto Fonseca (Dez/2003).

O Senado da Câmara parecia se orgulhar ao atender às solicitações do povo, o que, aliás, fica claro na inscrição latina que coroa o chafariz dos Contos: Is Quae Potatu Cole Gens Pleno Ore Senatum Securi Ut Sitis Nam Facit Ille Sitis, ou seja, "Povo que vais beber, louva de boca cheia o Senado porque tens sede e ele a faz cessar"(Lima, 1981, p. 31) (FIG. 4). A respeito desta inscrição, o viajante britânico Richard Burton emitiu um curioso comentário: "A água é melhor que o latim” (Burton, 1977, p. 301). Outro chafariz setecentista (o do Bonfim) possui uma inscrição latina que contém teores de propa- 
ganda política similares a do chafariz dos Contos.: Curia Curat, Amat, Fabricat, Propinat, Abhorret, Nos Libertatem, Staquq, Flu (...) Setim, ou seja, "O Senado (cúria) cuida de nós, ama a abundância, fabrica os tanques, dá a beber as águas correntes, aborrece a sede" (Lima, 1981, p. 43).

Uma dificuldade que se impunha ao Senado da Câmara - pode-se conjecturar - consistia da falta de informações sobre a disponibilidade hídrica dos mananciais, dentre outros dados hidrológicos imprescindíveis ao gerenciamento dos recursos hídricos - como se sabe nos dias de hoje e já se sabia nos dias de Frontinus na Roma antiga (Frontinus, 1983). Nas pesquisas realizadas no Arquivo Público Mineiro - fundos da Câmara Municipal de Ouro Preto e Seção Colonial - não foi observado qualquer documento, ou menção a documento, que trate de medições dos mananciais, do consumo per capita, dentre mais.

Não se pode dizer, entretanto, que não havia a preocupação do poder público com o consumo da água da população, pois a concessão de água a particulares dependia da quantidade requerida pelo mesmo. É curioso notar, porém, que o critério estabelecido para a concessão da água a particulares além do pagamento de uma quantia que variava entre 10 e 40 oitavas de ouro ${ }^{7}$ - não era a vazão "tirada" do encanamento público, mas a seção circular do cano que chegava à residência. As seções, em geral, pedidas eram o "anel" e a "pena" de água, as quais, em meados do século XIX em Portugal, correspondiam às dimensões expressas na FIG. 5.

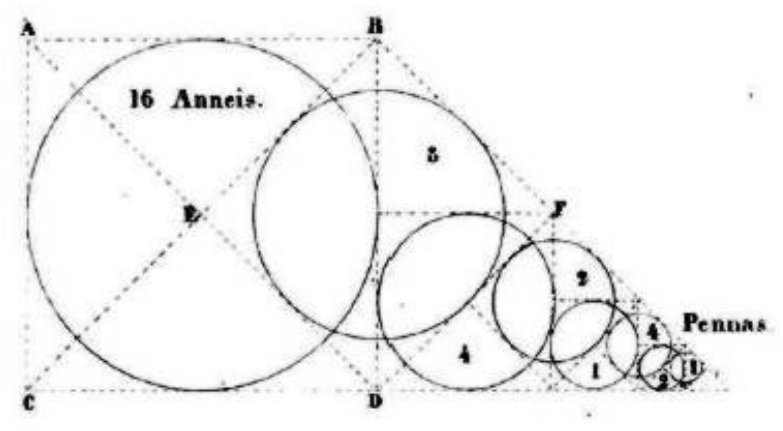

Figura 5 - Figura que representa a manilha d'água dividida em anéis e penas. Fora de escala. Fonte: Andrade (1851).

\footnotetext{
${ }^{7}$ Valores baseados em uma série de aproximadamente 20 registros de "compra de água" localizados no fundo da Câmara Municipal de Ouro Preto no Arquivo Público Mineiro.
}

De acordo com Andrade (1851), "o círculo maior é a manilha, que tem um palmo de circunferência, e o seu diâmetro são 7/22, e contém 16 anéis". É difícil atualizar o valor dessas seções para centímetros quadrados, pois as medidas variavam de lugar para lugar e de época para época. Se se dá ao palmo o valor que ele hoje possui, isto é, $22 \mathrm{~cm}$, entende-se que um anel de água correspondia a 2,41 $\mathrm{cm} 2$, e a pena, a $0,30 \mathrm{~cm} 2$ de diâmetro ${ }^{8}$. As medidas, em geral, utilizadas para os líquidos eram o almude, que contém doze canadas, que, por sua vez, contém quatro quatrilhos. Cumpre observar, porém, que "o quatrilho da Bahia no Brasil é uma canada de Lisboa" (Bluteau, 1712).

Outra dificuldade que se impunha ao Senado da Câmara de Vila Rica era a de conciliar os interesses dos mineradores com os interesses de abastecimento doméstico. A forte dependência que a mineração tinha da água suscitou diversos conflitos de uso, inclusive na sede urbana (Fonseca e Prado Filho, 2006). Dentre os manuscritos identificados na pesquisa que evidenciavam estes conflitos, um destaca-se pelo que tem de pitoresco. Disseram uns moradores do bairro Ouro Podre e seus vizinhos, posseiros de uma fonte há mais de trinta e seis anos, que uns mineradores, dentre eles Manoel Francisco Lisboa $^{9}$, se instalaram nas imediações da dita fonte, entulhando o caminho com os desmontes das minas e, assim, atrapalhando os escravos a irem pegar a água. Como se não bastasse - disseram os moradores - os mineradores colocaram um cachorro, o qual estava mordendo os escravos que por ali passavam (Representação... 1746b).

Outros problemas, por certo, aconteceram, embora não tenham sido registrados ou recebido o tratamento necessário do Senado da Câmara. Um dos mais relevantes, é de se conjecturar, foi a questão da transmissão de doenças pela ingestão de água contaminada nas minas. Luís Gomes Ferreira, um cirurgião que esteve em Vila Rica no princípio do século XVIII afirma que as doenças mais comuns entre os negros de Vila Rica eram as "pontadas pleurísticas", isto é, verminoses, ou, nas palavras do próprio Ferreira (2002, p. 234), "enchimento de estômago, lombrigas, corrupção do bicho e alguma obstrução". Entre as causas dessas "pontadas”, ele atribuiu, como principal, a condição de trabalho dos negros. Pois

\section{(...) uns habitam dentro da água, como são os}

\footnotetext{
${ }^{8}$ Os autores mediram a área circular de uma pena de água ainda em uso em Ouro Preto - e obtiveram: 0,35 cm2.

${ }^{9} \mathrm{Ou}$ o pai de Aleijadinho ou alguém com o nome idêntico.
} 
mineiros que mineram nas partes baixas da terra $e$ veios dela, outros feitos toupeiras, minerando por baixo da terra, uns em altura, de fundo, cinqüenta, oitenta e mais de cem palmos, outros pelo comprimento em estradas subterrâneas muitos mais, que muitas vezes chegam a seiscentos e a setecentos; lá trabalham, lá comem e lá dormem muitas vezes (...) (Ferreira, 2002, p. 229-230)

É difícil de acreditar que os negros, nessas minas, bebiam outra água que não fosse a que se lhes aparecia pelos meatos da terra e que servia ao mesmo tempo de escoadouro para os excrementos e demais dejetos. A ingestão de água contaminada, muito provavelmente, foi crítica e determinou o adoecimento de muitos escravos. Nesta pesquisa, porém, não foi detectado qualquer documento que atestasse a preocupação do Senado ou da Coroa em mitigar ou, ao menos, tratar dessa questão. Parte disto pode ter explicação no fato de que a microbiologia ainda era muito incipiente na época, quando ainda predominava a teoria dos miasmas, segundo a qual as doenças eram transmitas por vapores e ares contaminados com matérias decompostas (miasmata). A correlação entre ingestão de água contaminada e transmissão de doenças apenas obteve evidenciação científica em meados do século XIX com a publicação do Mode of communication of cholera de John Snow (1813-58).

Com o intuito de coibir as irregularidades e conflitos no abastecimento de água, o Senado da Câmara incluía nas posturas municipais diversos artigos regulando a questão do uso da água. Algumas destas, referentes ao ano de 1795 , foram transcritas por Lopes (1955)

Os moradores nesta Vila são obrigados a limpar as suas testadas, e lhes ordenamos que não lancem [sic] coisas imundas nas ruas ou becos públicos, nem nos canos que deságuam para elas debaixo da pena de meia oitava de ouro de condenação que se aumentará conforme a reincidência na culpa, paga da cadeia. [/] Toda a pessoa que se achar lavando roupas, ou outra qualquer coisa nos tanques dos chafarizes desta vila, onde bebem as cavalgaduras, com gravissimo prejuizo delas, será condenada em uma oitava de ouro. (p. 161163)

Quem não atendesse ao disposto nessas e noutras posturas podia ser preso ou punido, conforme o determinado. Assim aconteceu com Veríssimo Dias Corrêa em 1746, que, depois de encanar, sem licença do Senado, uma água defronte da Casa da Ópera, foi mandado para a cadeia pública, só saindo depois de 8 dias sob a justificativa de que desconhecia a lei (Solicitação... 1746). E também com João de Sá Bernardes, "por ter sido desobediente ao que por este Senado se lhe mandou em vários despachos sobre o Registro de uma porção de água deste Senado de que se estava utilizando para o seu quintal” (Reclamação... 1746).

De maneira geral, as pesquisas realizadas compravam que a demanda por água durante o ciclo do ouro foi intensa não apenas nos serviços de mineração, mas também nos novos centros urbanos. No caso de Vila Rica, esta se traduziu na construção de chafarizes públicos e particulares, na cobrança de taxas pela posse de água pública e na instauração de uma legislação coibindo irregularidades no uso da água.

\section{Quadro 1 - Elogios de estrangeiros e viajantes à água de Ouro Preto no século XIX.}

\begin{tabular}{l|l}
\hline $\begin{array}{l}\text { Saint Hilaire } \\
(2000, \text { p. 73) }\end{array}$ & $\begin{array}{l}\text { Vila Rica goza de uma vantagem ina- } \\
\text { preciável. Por todos os lados uma água } \\
\text { excelente brota dos morros em que foi } \\
\text { construída essa vila. }\end{array}$ \\
\hline $\begin{array}{l}\text { Luccock } \\
(1975, \text { p. 332) }\end{array}$ & $\begin{array}{l}\text { As fontes públicas, catorze ao todo, } \\
\text { acham-se dispersas pela cidade; são } \\
\text { geralmente belas construções e provi- } \\
\text { das abundantemente de água pura. }\end{array}$ \\
\hline Gardner & $\begin{array}{l}\text { A cidade é abundantemente suprida de } \\
\text { água de excelente qualidade, havendo } \\
\text { uma fonte quase em cada rua. }\end{array}$ \\
\hline Halfeld & $\begin{array}{l}\text { (...) há chafarizes públicos em bom } \\
\text { número (dos quais o mais belo fica } \\
\text { nesse mesmo largo), que fornece água } \\
\text { (1998, p. 139) }\end{array}$ \\
\hline
\end{tabular}

Destaca-se, porém, que, apesar de todos os problemas, a água de Ouro Preto obteve uma relativa fama no período imperial, sendo bastante elogiada quanto aos seus aspectos qualitativos e quantitativos. Dentre as mais expressivas frases proferidas sobre a água da cidade nesta época, destaca-se a repetida pelo viajante Richard Burton (1977, p. 302) quando ali esteve em meados do século XIX: “(...) em Ouro Preto, só há duas coisas boas: a cadeia e a água”. O Quadro 1 a seguir explicita outros elogios prestados à água da vila por vários estrangeiros e viajantes do século XIX.

Com o término do ciclo do ouro, grande parte da população deixou a cidade e, neste contexto, as fontes e nascentes existentes se tornaram mais 
do que suficientes para a demanda. E com a redução das interferências nos cursos d'águas ocasionadas pelas minas de ouro, a qualidade da água também foi favorecida. Ao cabo de um século, os recursos hídricos mostraram-se resilientes ao impacto do empreendimento mineiro e do crescimento populacional.

\section{CONSIDERAÇÕES FINAIS}

Passados três séculos, Ouro Preto ainda guarda muito do seu antigo sistema de abastecimento de água. Ainda hoje, são diversas (cerca de 15) as captações que abastecem o centro urbano. Algumas dessas estão situadas em antigas minas e prescindem do devido tratamento de qualidade da água. Em certas regiões, chafarizes são utilizados pela população, e, curiosamente, a existência de "penas" de água, em vez de medidores de vazão, ainda predomina nas residências.

Todavia, com o forte crescimento populacional e alterações do uso do solo ocorridos no século XX, tais características têm se mostrado incompatíveis com a atual legislação e com as demandas do público. Em entrevistas ${ }^{10} \mathrm{e}$ inspeções de campo realizadas no sistema de abastecimento de água do centro urbano, com o auxílio do Departamento de Águas e Esgotos da prefeitura, foram detectados diversos problemas, a saber:

- $\quad$ inexistência de monitoramento sistemático e abrangente da qualidade da água fornecida à população, de modo a garantir o atendimento aos padrões de potabilidade do Ministério da Saúde (Portaria MS 518/2004). Tal fragilidade torna-se preocupante tendo em vista recentes estudos que identificaram alarmantes concentrações de cianetos em antigas minas de ouro da região (Borba, 2002);

- $\quad$ falta de medição de consumo de água, bem como cobrança precária e irrisória pelos serviços de fornecimento de água para a população;

- $\quad$ mau estado de conservação de alguns reservatórios, trechos de tubulações, laboratórios, chafarizes, captações e estações de trata-

\footnotetext{
${ }^{10}$ As últimas entrevistas foram realizadas em 06 de Maio de 2008 com a Diretora de Gestão, Kenny Murta, e com o químico, Cláudio Soutto Mayor, ambos do SEMAE de Ouro Preto.
}

mento de água;

- ocorrências de eventuais interrupções no fornecimento de água em algumas regiões e em períodos de pico de demanda (tais como em ocasiões festivas);

- $\quad$ existência de lançamento de esgotos sanitários domésticos sem tratamento próximo a pontos de captação de água em minas de encostas; e

- $\quad$ elevada taxa de consumo de água per capita, estimada por técnicos da prefeitura entre 450 e 500 litros por habitante ao dia.

Em reação a problemas como estes, a mídia, notadamente local, publicou diversas notícias alarmantes ao longo da última década. Também foi criado um núcleo de pesquisas em recursos hídricos na Universidade Federal de Ouro Preto em 2001, o qual tem contribuído para a investigação de diversos aspectos do sistema de águas e esgotos da cidade.

Mais recentemente, em fevereiro de 2005, a prefeitura de Ouro Preto criou o Serviço Municipal de Águas e

Esgotos (SEMAE), o qual, após captar recursos junto ao Banco de Desenvolvimento de Minas Gerais (BDMG) e ao Banco Nacional de Desenvolvimento Econômico e Social (BNDES), está implantando duas importantes obras na cidade: o tratamento dos esgotos sanitários do centro urbano e a instalação de uma nova estação de tratamento de água. Estas melhorias constituem significativos avanços da atual gestão municipal, mas representam apenas parte das medidas que serão necessárias para sanar os atuais problemas.

Os chafarizes públicos, por exemplo, apesar de constituírem importantes serviços e monumentos da cidade, necessitam de urgentes melhorias. As pesquisas de campo puderam comprovar que apenas a menor parte desses chafarizes está vertendo água e recebendo segurança, manutenção e conservação. Vários deles estão visivelmente abandonados, sofrendo diversos tipos de depredação. Cumpre destacar que, durante as pesquisas, a carranca e parte das ruínas do antigo chafariz do Jardim Botânico foram roubadas, para o prejuízo da cidade.

Espera-se que as informações aqui levantadas possam ser observadas em futuras políticas e ações técnicas e educativas relacionadas ao saneamento da cidade. No caso de Ouro Preto, que foi decretada Monumento Nacional em 1933 e é considerada uma cidade Patrimônio Cultural da Humanidade pela UNESCO, variáveis históricas e culturais são fundamentais. 


\section{AGRADECIMENTOS}

Os autores gostariam de agradecer a Universidade Federal de Ouro Preto pela bolsa concedida para a realização das pesquisas, bem como a todos os entrevistados pela solicitude demonstrada.

\section{REFERÊNCIAS}

ALMEIDA, C. M. D. Codigo Philipino ou ordenações e leis do reino de Portugal: Recompiladas por mandado d'el rey d. Philippe I. 14ed (segundo a 1a de 1603 e a 9a de Coimbra de 1824). Rio de Janeiro: Typographia do Instituto Philomathico, 1870.

ANDRADE, J. S. V. D. Memoria sobre chafarizes, bicas, fonte e poços públicos de Lisboa, Belém e muitos logares do termo: Oferecida à ex. Ma camara municipal de Lisboa por josé Sergio Velloso d'Andrade. Lisboa: Imprensa Vilviana [Exemplar raro pertencente ao Arquivo do Museu do Paço Imperial, RJ], 1851.

ANTONIL, A. J. Cultura e opulência no Brasil por suas drogas e minas. Belo Horizonte; São Paulo: Itatiaia; Edusp, 1982. [1711]

BLUTEAU, D. R. Vocabulario Portuguez e Latino. Coimbra: Collegio das Artes da Companhia de JESU [sic] 1712.

BORBA, Ricardo Perobelli. Arsênio em ambiente superficial: processos geoquímicos naturais e antropogênicos em uma área de mineração aurífera. 2002. Tese (Doutorado em Geociências) - Instituto de Geociências da Universidade de Campinas, Campinas, 2002.

BURTON, R. F. Viagem do Rio de Janeiro a morro velho. Belo Horizonte: Itatiaia, 1977. [1867]

CARVALHO, F. D. Pontes e chafarizes de Villa Rica. Belo Horizonte: Edições Históricas, 1936.

CASTRO, M. L. A. C. D. A especialização do espaço no final do século XIX e início do século XX nas edificações de Ouro Preto: O advento dos banheiros. 2003. 197 (Mestrado em História e Teoria da Arquitetura). Escola de Arquitetura, Universidade Federal de Minas Gerais, Belo Horizonte.

DEBRET, J. B. Viagem pitoresca através do Brasil. Belo Horizonte: Itatiaia, 1972. [1834-1839]

FERRAND, P. O ouro em Minas Gerais. Belo Horizonte: Fundação João Pinheiro, Centros de Estudos Históricos e Culturais, 1998. [1894]

FERREIRA, L. G. Erário mineral. Rio de Janeiro: Fundação Oswaldo Cruz, 2002. [1735]

FONSECA, A. D. F. C.; PRADO FILHO, J. F. D. Um importante episódio na história da gestão dos recursos hídri- cos no Brasil: 0 controle da coroa portuguesa sobre 0 uso da água nas minas de ouro coloniais. Revista Brasileira de Recursos Hídricos, v. 11, n. 3, p. 5-14, 2006.

FONTES... Fontes e chafarizes do brasil. São Bernardo do Campo: Mercedes-Benz do Brasil, 1991.

FRONTINUS, S. J. De aquis urbis romae - das águas da cidad de Roma (97 d.C. - 104 d.C.). São Paulo: CETESB, 1983. 71

GARDNER, G. Viagem ao interior do brasil. Belo Horizonte/São Paulo: Itatiaia/Edusp, 1975.

HALFELD, H. G. F.; TSCHUDI, J. J. V. A província brasileira de minas gerais. Belo Horizonte: Fundação João Pinheiro, 1998.

HOLANDA, S. B. D. Raízes do Brasil. São Paulo: Companhia das Letras, 2002.

LATERZA, M. Aspectos da gárgula barroca mineira. Revista Barroco, v. 12, p. 197-217, 1983.

LIMA, J. A. C. D. A. Ouro Preto revisitada: Roteiro histórico de seus monumentos esquecidos. Belo Horizonte: Conselho de Extensão da Universidade Federal de Minas Gerais, 1981.

LOPES, F. A. Os palácios de Vila Rica: Ouro preto no ciclo do ouro. Belo Horizonte: 1955.

LUCCOCK, J. Notas sobre o Rio de Janeiro e partes meridionais do Brasil. Belo Horizonte /São Paulo: Itatiaia/ Edusp, 1975.

MALTIEIRA, J. D. Ouro Preto: Relicário do Brasil. Rio de Janeiro: Bralis, 1971.

MARIANO FILHO, J. M. Os três chafarizes de mestre valentim. Rio de Janeiro: Artes Gráficas C. Mendes Júnior, 1943.

Mappa de Villa Rica (cópia do original do arquivo do exército). Arquivo Público Mineiro. Mapas avulsos de Ouro Preto. Belo Horizonte, 1785-1800.

MELLO, S. D. Barroco mineiro. Rio de Janeiro: Brasiliense, 1985.

MMA/SRH. Panorama e estado dos recursos hídricos do brasil. In: MMA/SRH (Ed.). Plano nacional de recursos hídricos. Brasília: Ministério do Meio Ambiente; Secretaria de Recursos Hídricos, v.1, 2006.

MOREIRA, G. A. As águas no direito civil Português. Livro I: Propriedade das águas. Coimbra: Edição do autor, 1920. [Exemplar raro disponível na Biblioteca Nacional, Rio de Janeiro]

PRISCOLI, J. D. Water and civilization: Using history to reframe water policy debates and to build a new ecological realism. Water Policy, v. 1, n. 1998, p. 623636, 1998.

[Reclamação sobre mandado de prisão pelo uso ilícito de água pública]. Arquivo Público Mineiro. CMOP/Caixa 19. Documento 46. Belo Horizonte, 1746.

[Representação de moradores do bairro rosário sobre a necessidade de uma fonte]. Arquivo Público Mineiro. 
CMOP/Caixa 16. Documento 44. Belo Horizonte, $1745 \mathrm{a}$.

[Representação de moradores dos bairros piçarrão e alto da cruz sobre falta de água em chafariz]. Arquivo Público Mineiro. CMOP/Caixa 16. Documento 72. Belo Horizonte, $1745 \mathrm{~b}$.

[Representação de moradores do bairro padre faria sobre problemas com valos de esgotos]. Arquivo Público Mineiro. CMOP/Caixa 19. Documento 52. 1746a.

[Representação de moradores do Ouro Podre sobre conflitos com mineradores pela posse de uma fonte de água]. Arquivo Público Mineiro. CMOP/Caixa 18. Documento 20. Belo Horizonte, 1746b.

[Representação de moradores do bairro Antônio Dias sobre o estado de conservação de fontes]. Arquivo Público Mineiro. CMOP/Caixa 77. Documento 85. Belo Horizonte, 1804.

[Representação de moradores do morro do Pau Doce sobre extravio de águas públicas]. Arquivo Público Mineiro. CMOP/Caixa 79. Documento 37. Belo Horizonte, 1806.

[Requerimento particular de porção de água]. Arquivo Público Mineiro. CMOP/Caixa 57. Documento 12. Belo Horizonte, 1782.

SAINT-HILAIRE, A. D. Viagem pelas províncias do Rio de Janeiro e Minas Gerais. Belo Horizonte/São Paulo: Itatiaia/Edusp, 2000. [1823]

SALES, F. T. D. Vila rica do pilar: Um roteiro de Ouro Preto. Belo Horizonte: Itatiaia Limitada, 1965.

SILVA, J. R. D. Evolução do sistema de esgotos do rio de janeiro. Revista Engenharia Sanitária, v. 14, n. 13, p. 220-227, 1975.

[Solicitação de Veríssimo dias Corrêa para sair da cadeia, por não conhecer a lei]. Arquivo Público Mineiro.

CMOP/Caixa 18. Documento 59. Belo Horizonte, 1746.

SYMMES, M. Fountains, splash, and spectacle: Water and design from the renaissance to the present. Singapure: Smithsonian Institution, 1998.

[Termo de arrematação do serviço de conservação de fontes e calçadas]. Arquivo Público Mineiro. CMOP/Caixa 32. Documento 50. Belo Horizonte, 1750.

UNEP. Global environmental outlook (GEO) 4: Environment for development. Nairobi: United Nations Environment Programme, 2007.

VASCONCELOS, S. D. Vila Rica: formação e desenvolvimento. São Paulo: Editora Perspectiva, 1977.

Vida e obra de Antônio Francisco Lisboa, o Aleijadinho. São Paulo: Cia. Ed. Nacional, 1979.

\section{Ouro Preto, Clean Water: Domestic Water Supply at the Epicenter of Brazil's Gold Rush}

\section{ABSTRACT}

This paper addresses the domestic water supply in the town of Ouro Preto, the epicenter of Brazil's gold rush. One of the most significant episodes in the history of water resources management in colonial Brazil took place at this region, where a primitive system of water allocation and prioritization of use was devised. In this context, this paper sought to understand the problems in the water supply in the village (known at the time as Vila Rica) and how the local public service reacted to them. The methods encompassed literature review, interviews, field inspections and an extensive archival research. Results show that demand for water was intense not only in the gold mines, but also in the urban centers created at that time. In the case of Vila Rica, that meant the construction of public and private water fountains, the taxation of public water use and the establishment of by-laws inhibiting irregular water uses. Identified documents prove that some water users were sent to jail or condemned to pay fines for not obeying the law in Vila Rica. Some of the technical and cultural aspects of the water supply system in the village were found to differ from those in the coastal cities. After almost three centuries, Ouro Preto's water supply system still keeps many of its old characteristics, such as several sources of extraction, not measuring consumption, and problems related to the quantity and quality of the water supplied. It is expected that the information presented here may help the recently created Municipal Water and Sewage Service and other sanitation institutions to consider historic and cultural variables in their decision-making, which are essential in the case of World Cultural Heritage cities, such as Ouro Preto.

Key-words: HIstory of Water; Water Supply; Sanitation, Ouro Preto $(M G)$. 